\title{
Short-term Fate of Dietary Dieldrin in the Digestive Tract of Juvenile Lake Trout (Salvelinus namaycush)
}

by

Donald J. STEWART ${ }^{1}$ and Roy A. Stein ${ }^{2}$

Great Lakes Fishery Laboratory

Bureau of Sport Fisheries and Wildlife

Ann Arbor, Mich. 48107

Short-term fate of dietary dieldrin in the digestive tract of fishes is poorly known. Studies of the uptake, distribution, and elimination of chlorinated hydrocarbons have suggested that uptake or degradation is rapid in the intestine (GROSS 1969; MACEK et al. 1970; GRZENDA et al. 1970, 1971). The present study was designed to determine the short-term fate of a single oral dose of dieldrin in the digestive tract of lake trout (Salvelinus namaycush).

\section{Materials and Methods}

Juvenile lake trout (average weight $13.5 \pm 3.1 \mathrm{~g}$ ) obtained from the Jordan River National Fish Hatchery were acclimated in an experimental tank at $8 \mathrm{C}$ for 30 days and fed Oregon moist pellets (3\% of body weight per day). After acclimation, fish were starved for $60 \mathrm{hr}$. Eight groups of 10 individually fin-clipped fish were placed in perforated buckets suspended in the experimental tank. Throughout acclimation and experimentation, photoperiod was constant (12L : 12D) and dissolved oxygen remained near saturation.

Juvenile lake trout to be used as the source of dieldrin were exposed in a constant flow system to about 700 parts per trillion dieldrin for 2 weeks. The flesh of the trout was removed, macerated, and held at $4 \mathrm{C}$ for $4 \mathrm{hr}$.

The macerated flesh was injected into the stomachs of the experimental lake trout with Pasteur pipettes coupled to flexible polyethylene tubing. Approximately $0.5 \mathrm{~g}$ of flesh with an average dieldrin concentration of $1.05 \pm 0.09 \mathrm{ppm}$ was placed in each pipette and weighed to the nearest milligram. After anesthetizing a trout, we inserted the tubing through the esophagus into the stomach, and extruded the food. The fish was transferred to a recovery tank and the pipette was reweighed to determine the quantity of food injected. Concentration of dieldrin in the injected food was determined by analyzing samples from 10 pipettes. No fish showed symptoms of distress during the experiments. In the rare cases of regurgitation, the ejected food was recovered, blotted, and returned to the appropriate pipette before the pipette was reweighed. To estimate losses from degradation, we injected the contents of each of 12 pipettes into separate test tubes, sealed the tubes, and suspended them in the experimental tank.

1) Present address: School of Natural Resources, University of Michigan, Ann Arbor, Michigan 48104.

2) Present address: Laboratory of Limnology, University of Wisconsin, Madison, Wisconsin 53706. 
Sample groups of 10 fish were sacrificed after intervals of $3,6,12,18,24,36,48$, and $60 \mathrm{hr}$, and held on ice until contents of the digestive tract could be recovered (usually less than $2 \mathrm{hr}$ ). To prevent movement of ingested material during dissection, we placed hemostats at the anterior end of the stomach, at the pyloric valve, and at the posterior end of the intestine. Contents of the stomach and intestine were removed and weighed to the nearest milligram.

After samples from the digestive tract were saponified in a1coholic $\mathrm{KOH}$ and extracted with hexane, the amounts of dieldrin were determined by gas chromatography. Saponification and chromatographic techniques were those used by REINERT (1970), except that the Florisil clean-up was not necessary. Water samples of 3 liters were extracted by shaking with $100 \mathrm{ml}$ of hexane for $3 \mathrm{~min}$; the hexane was collected and concentrated to $0.1 \mathrm{ml}$ prior to gas chromatographic analysis.

\section{Results and Discussion}

The decline of dieldrin in the stomach paralleled the decline in the amount of food (Fig. $1 a, b$ ); even after most food had passed into the intestine, however, little or no dieldrin was recovered there (Fig. 1c,d). This finding indicated a rapid uptake or degradation of dieldrin in the pyloric caecal region and demonstrated that, under the experimental conditions of this study, defecation of dieldrin was minimal.

Control samples held in test tubes showed no significant loss ( $p<0.05)$ of dieldrin during the experiment. Water samples taken from the experimental tank during acclimation and experimentation contained no dieldrin.

Inasmuch as fatty tissues of fish are considered to be primary storage sites for chlorinated hydrocarbons (HAMELINK et al. 1971), the dietary uptake of dieldrin by the experimental fish would have been expected to parallel the absorption of fats. It is generally accepted that fats are absorbed in the anterior portion of the intestine (IWAI 1968; WESTERN 1969, 1971). Our results thus did not differ from expectations. The pyloric caeca have been indicated as primary sites of dieldrin absorption in the green sunfish, Lepomis cyanellus (GROSS 1969).

\section{Acknowledgments}

We thank Robert $E$. Reinert and James F. Kitchell for reviewing the manuscript and Frank F. Hooper for encouragement and advice. 


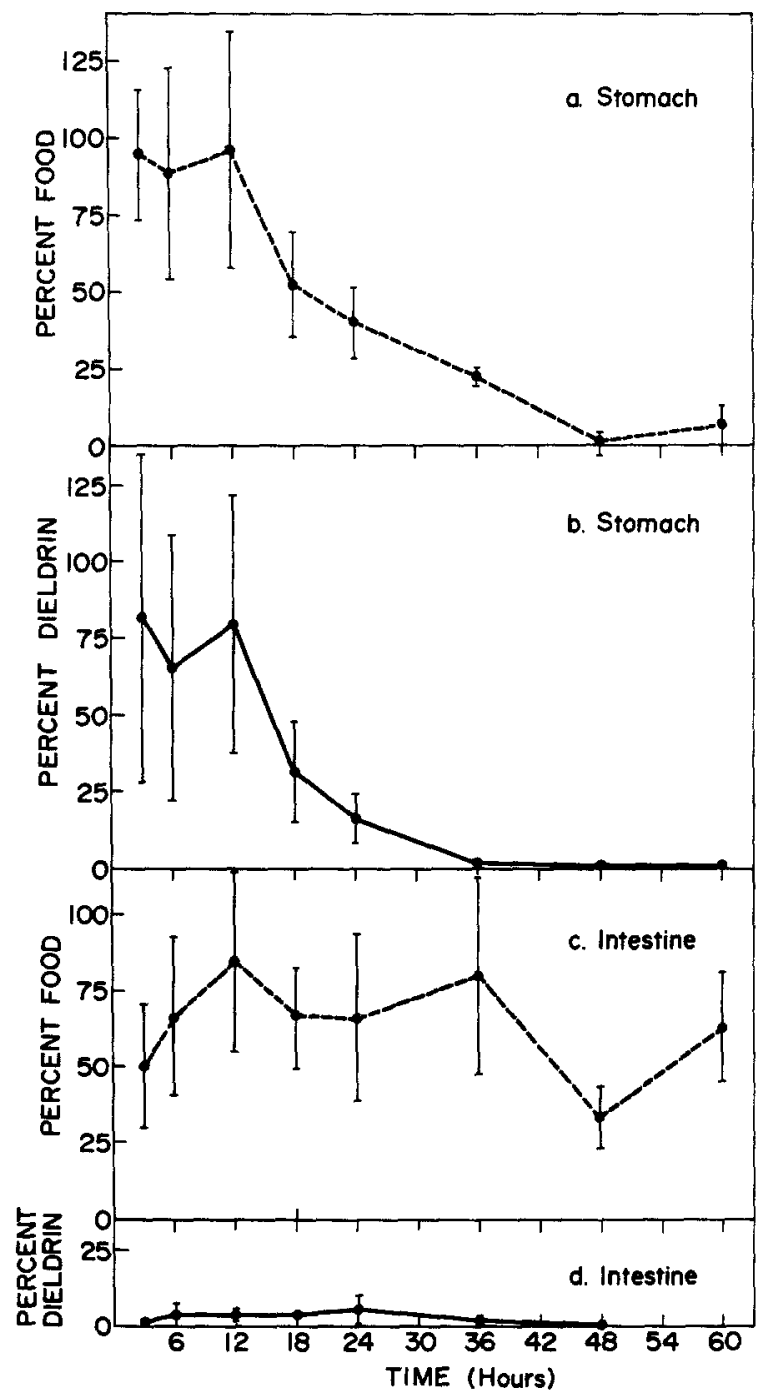

Figure 1. Short-term recovery of food $(a, c)$ and dieldrin $(b, d)$ from the stomach $(a, b)$ and intestine $(c, d)$ of juvenile lake trout after a force-fed meal of macerated trout flesh containing an average of $1.05 \mathrm{ppm}$ of dieldrin. Vertical bars show standard deviations. (During the first $36 \mathrm{hr}$, the presence of pellet food in the intestines of some fish resulted in the recovery of more food than was injected.) 


\section{References}

GROSS, W.L: Distribution and elimination of dieldrin by green sunfish (Lepomis cyanellus Rafinesque) following administration of a single oral dose. Ph.D. Thesis, Mich. State Univ., East Iansing 1969.

GRZENDA, A.R., D.F. PARIS, and W.J. TAYLOR: Trans. Am. Fish. Soc. 99, $383(1970)$.

GRZENDA, A.R., W.J. TAYLOR, and D.F. PARIS: Trans. Am. Fish. SOC. 100,215 (1971).

HAMELINK, J.L., R.C. WAYBRANT, and R.C. BALI: Trans. Am. Fish. Soc. 100,207 (1971).

IWAI, T.: Bull. Jap. Soc. Sci. Fish. 34, 973 (1968).

MACEK, R.J., C.R. RODGERS, D.I. STALIING, and S. KORN: Trans. Am. Fish. Soc. 99, 689 (1970).

REINERT, R.E.: Pestic. Monit. J. 3, 233 (1970).

WESTERN, J.R.H.: Acta Zool. (Stockh.) 50, 185 (1969).

WESTERN, J.R.H.: J. Fish. Biol. 3 , 225 (1971). 